\title{
A Comparison of OpenURL Link Resolvers: the Results of a University of Connecticut Libraries Environmental Scan
}

\author{
Jill Livingston \\ University of Connecticut Libraries \\ Deborah Sanford \\ University of Connecticut Libraries \\ David Bretthauer \\ University of Connecticut Libraries, dave.bretthauer@uconn.edu
}

Follow this and additional works at: https://opencommons.uconn.edu/libr_pubs

Part of the Library and Information Science Commons

\section{Recommended Citation}

Livingston, Jill; Sanford, Deborah ; and Bretthauer, David , "A Comparison of OpenURL Link Resolvers: the Results of a University of Connecticut Libraries Environmental Scan" (2006). Published Works. 5.

https://opencommons.uconn.edu/libr_pubs/5 


\section{A Comparison of OpenURL Link Resolvers: the results of a University of Connecticut Libraries environmental scan}

Jill Livingston*, Deborah Sanford, and Dave Bretthauer.

University of Connecticut, Homer Babbidge Library, 369 Fairfield Road, Storrs, Connecticut 06269

* Corresponding author.

E-mail addresses: jill.livingston@uconn.edu; deborah.sanford@uconn.edu; dave.bretthauer@uconn.edu 


\begin{abstract}
This study examines the system architecture and capabilities of commercially available OpenURL link resolvers. These emerging technological tools are designed to increase use of library collections by automating the process of locating and accessing library holdings. Data for the study, largely experiential feedback received from libraries employing OpenURL link resolvers, was gathered through a series of evaluative activities. These included a preliminary literature review, Web survey, follow-up e-mail survey, and on-site visits to libraries. Results were analyzed within the context of the University of Connecticut Libraries' resources and needs. Analysis revealed wide variation in library experiences with and perception of product functionality and performance, as well as requisite staff and financial investments.
\end{abstract}

Keywords: OpenURL link resolvers, linking, SFX, LinkFinderPlus, Article Linker

\title{
Introduction
}

The University of Connecticut Libraries (UCL) form the largest public research collection in the state of Connecticut. The collection contains over 2.5 million print volumes, thousands of electronic books, approximately 7,000 currently received print periodicals, over 25,000 electronic journals, 2.8 million units of microform, 35,000 reference sources, 180,000 maps, and an array of electronic information sources. The UCL also license approximately 250 electronic databases, many of which contain the full-text of research journals, monographs, and historic documents. 
The University's main library, the Homer Babbidge Library, serves both graduate and undergraduate programs. Other libraries on the Storrs campus include the Music \& Dramatic Arts Library, the Pharmacy Library, and the Archives \& Special Collections at the Dodd Research Center. Each of the University's regional campuses-Avery Point, Stamford, Torrington, Waterbury, and West Hartford—maintains a library dedicated to serving the programs at those sites. All the UConn Libraries share a single catalog and form a single collection; each library unit serves as a full gateway to the entire collection. Networked resources, licensed from a centralized technical services department at the Babbidge Library, are available to all members of the University community, with off campus access available via the University's Virtual Private Network.

In spring 2003, the UCL purchased and installed LinkFinderPlus (LFP). LFP was configured to provide article level linking to journals contained within the LFP KnowledgeBase and to run ISSN searches against the library catalog. A custom-scripted self-populating interlibrary loan form was designed to function along with LFP. Later, because only a small percentage of ISSNs matched against the Knowledgebase, another ISSN search was added to run against the library's electronic journals holdings list. Unfortunately, by March 2005, even after a significant amount of troubleshooting and time invested by staff, the overall functionality of LFP was very low. At best, staff estimated that LFP could accurately resolve $50-60 \%$ of full-text e-journal holdings.

The cause of problems was attributed to product architecture, factors related to the adolescence of the OpenURL standards and linking technology, and limited staff resources possessing appropriate skill levels. It was unclear to what extent the different 
factors contributed to the overall state of performance. It was also unknown whether other OpenURL link resolvers performed better/worse or required more/less of staff time and skill to operate. To answer these questions, library staff made a determination to undertake a comparative investigation of all commercially available OpenURL link resolvers.

After a preliminary literature review, a formal assessment was undertaken. Data was gathered through electronic media and in-person. That which was used in analysis included:

- Web survey data pertaining to product performance and staff time and skill requirements.

- E-mail survey data regarding quantity of library electronic journal holdings and percentage that successfully linked at the article level from the link resolver, adequacy of staff time spent on product, and quality of customer service.

- Site visit data regarding features available in specific OpenURL link resolvers and their rate of success as well as library experiences with the product and link resolver provider.

\section{Literature Review}

A review of the literature was conducted to ascertain whether others had completed critical evaluations or comparisons of commercially available link resolver products with regards to installation efforts, patron interface customization, maintenance, functionality, 
or performance. Many articles are published on OpenURL linking technology. One set offers background information about the concepts and mechanisms of OpenURL link resolvers and related technologies such as federated searching, CrossRef, and Digital Object Identifiers (DOIs) [21, 2, 31, 5]. A particularly useful article by Chen (2004) [3] outlines problems with full-text sources used by serials systems, including OpenURL link resolvers. Problems identified include outdated or incorrect data provided by content providers, incorrect or incomplete embargo information, and no format or file-type information. Another set of articles provides overviews of the technology or descriptions of specific products $[16,34,24,19,7,9,18,25,8,20,1]$. The majority of product descriptions detail Ex Libris SFX and most tend to be promotional in nature, rather than critical. More useful for qualitative assessment are the articles that convey experiential information about implementing a link resolver $[4,28,15]$. Again, the majority deal with SFX, but these articles generally offer valuable information about staffing needs, present use, usability, problems encountered, and the challenges of maintaining OpenURL link resolvers. Singular in its scope, there was one article that very closely tied in with the aim of this study. A 2004 publication by Ferguson and Grogg [12] not only described link resolver technology, but went further to list features to consider when evaluating a link resolver. This article also charted important information about 11 major link resolver products, such as the year each was introduced, the number of current installations, and whether the key features described earlier in the article were available in each. It is important to note that while the Ferguson and Grogg article showed availability of features, it did not explore differences in functionality and performance of those features. A search of the Internet did not substantially add to the body of literature described 
above. It was, however, a useful reservoir of information about OpenURL link resolvers with small market share and it provided reinforcement in other cases by presenting more technology descriptions $[33,32]$ more product descriptions and screen captures $[6,10$, $11,29,13,14,17,22,23,26,27,30]$, and library-specific experiential information. Based on this literature review, it was concluded that there were no published critical comparisons of commercially available link resolver products in either the published professional literature or on the open Web.

\section{Methodology}

At the time of this study, there were 12 known commercially available link resolver products: the Colorado Alliance of Research Libraries (CARL) Gold Rush, Ebsco Publishing LinkSource, Endeavor Information Systems LinkFinderPlus (LFP), Ex Libris SFX, Fretwell-Downing Informatics $\mathrm{OL}^{2}$, Geac Library Solutions VLink, Innovative Interfaces WebBridge, Openly Informatics 1Cate, Ovid Technologies LinkSolver, Serials Solutions Article Linker, Sirsi Corporation Sirsi Resolver, TDNet TOUR. Evaluation of the products consisted of a three-step process: Web-based survey, e-mail survey, and site visits.

\section{Web Survey}

An 18-question Web-based survey (see appendix 1) was created, the purpose of which was threefold: to ascertain the amount of staff time and skill required to implement and operate the various OpenURL link resolvers on the market, to determine how well each product performed, and to determine how various problems inherent in OpenURL linking 
technology affected each product. The target recipients for the survey were members of listservs relevant to e-resource management issues, such as SERIALST and NASIG-L. SurveyMonkey was chosen as the Internet-based survey software because of its low cost, ease of use, survey options, analysis tools, and ability to be easily mass distributed.

The survey was designed to solicit the necessary information in as few questions as possible. To further reduce the time needed to complete the survey, most questions had multiple choice answers. This, it was hoped, would increase response rate. Where appropriate, only the 6 products identified in the Ferguson and Grogg article [12] as having 50 or more customers were listed as multiple choice options. Once completed, a link to the survey with a description of its purpose was e-mailed to several relevant library listservs including SERIALST, NASIG-L, Conntech, and ITIG-L (from ITIG ACRL/NEC).

\section{E-Mail Survey}

A 5-question follow-up survey was conducted via individually addressed e-mails to Web survey respondents (see appendix 2). The purpose of the e-mail survey was to clarify gray areas exposed by Web survey results. Specifically, the e-mail survey sought to determine quantity of library electronic journal holdings and percentage that successfully linked at the article level from the link resolver, whether staff time spent on link resolver operation was adequate, and perception of corporate customer service. 


\section{Site Visits}

Based on results of the Web and e-mail surveys, three products were selected for further investigation via on-site visits: Serials Solutions Article Linker, Endeavor LFP, and Ex Libris SFX. These products, in addition to being widely used in libraries, particularly those with large and diverse collections, were also deemed to be most compatible with UConn's Integrated Library System (ILS), Voyager, and Serials Management System, Serials Solutions. Products excluded from site visits because of minimal customer base and scarce or no survey feedback included $1 \mathrm{Cate}, \mathrm{OL}^{2}$, Sirsi Resolver, TOUR, and VLink. Two other products were excluded from further consideration because they were assessed to be comparable to products with which the UCL has more experience. These included WebBridge and LinkSource. Given a more lenient timeframe for conducting this study, both would have been included in the full analysis.

In order to adequately evaluate the capabilities of each product, only libraries that had fully implemented an OpenURL link resolver and considered it to work well were considered for visitation. Because of financial considerations, site selection was restricted to institutions in New England. Also, to mimic the UCL environment, preference was given to institutions with a large number of electronic databases and electronic journals in the humanities and sciences. Institutions with science-only holdings were considered an appropriate alternative. Based on these criteria, three sites were chosen for full group visits and two additional sites were visited by one team member. 
- SFX: Team visit to an institution in Massachusetts that serves both humanities and scientific disciplines and has access to approximately 10,000 electronic journals and 165 electronic databases.

- SFX: Individual visit to an institution in Connecticut that serves both humanities and scientific disciplines and has access to approximately 37,000 electronic journals and approximately 250 electronic databases.

- LFP: Team visit to an institution in Massachusetts that primarily serves the scientific disciplines and has access to approximately 2,000 electronic journals and 90 electronic databases.

- LFP: Individual visit to an institution in Massachusetts that primarily services the scientific disciplines and has access to approximately 30,000 electronic journals and 150 databases.

- Article Linker: Team visit to an institution in Rhode Island that serves both humanities and scientific disciplines and has access to 12,000 electronic journals and approximately 140 databases.

A script was formulated to gather critical and consistent information from each library. This was to be used as the basic tool for comparison; however, other information was gathered at each site beyond the core elements (see appendix 3). Additionally, 15 specific citations of various publications types were identified from 8 different databases and tested at each site to determine how accurately the link resolver responded. 


\section{Limits of the study}

Scope

While this study contributes to the existing body of OpenURL link resolver literature, it is not a comprehensive analysis of all available commercial OpenURL resolvers. Due to the purpose of the study, to assess viable options for the University of Connecticut Libraries and because of staff time limitations, products deemed not viable for use at the UCL were eliminated from consideration during the evaluative process. The Web survey conducted in this study was intended to solicit information on all commercially available OpenURL link resolvers; however, ultimately, only three of the products identified as most viable for implementation at the UCL were fully evaluated. It might have been particularly valuable to include WebBridge and LinkSource in the full analysis if time had permitted.

An additional weakness in the study is that OpenURL link resolvers are generally costly and time consuming for staff to implement and maintain and their employment greatly affects library patrons. It was therefore not possible to conduct a controlled investigation, whereby subjectivity and confounding variables could be eliminated. This study was observational, and carried with it those shortcomings inherent in all observational studies.

\section{Web Survey}

Though a total of 79 usable surveys were received, participation varied by link resolver and question. Five of the 12 known commercially available products, 1Cate, Gold Rush, 
LinkSolver, Sirsi Resolver, and TOUR received only one response and 2 other products, $\mathrm{OL}^{2}$ and VLink, received no responses. Also, inconclusive results were received in the following areas: quantity of library electronic journal holdings and percentage that successfully linked at the article level from the link resolver, whether staff time spent on link resolver operation was adequate, and perception of corporate customer service. These deficiencies necessitated a follow-up e-mail survey.

\section{E-Mail Survey}

Of the 79 Web survey respondents used, only 54 provided contact information and could be contacted to complete the follow-up e-mail survey. Of the 54, only 26 responded. Participation varied by product and question. There were no respondents from Gold Rush, LinkSolver, $\mathrm{OL}^{2}$, Sirsi Resolver, TOUR and VLink. 1Cate generated only 1 response and WebBridge generated 2. The most responses received for any product was 10 for SFX.

\section{Site Visits}

Because of cost, staff limitations and geographical restrictions, only the top 3 products under consideration, Article Linker, LFP, and SFX were designated to receive a full evaluative site visit. Institutions given preference were those that that had access to a large number of databases and electronic journals in the humanities and sciences. Because the majority of the UCL's electronic holdings are in the sciences, institutions serving science disciplines only were considered appropriate as well. Also, only the top two products under consideration, LFP and SFX received two site visits, the second of 
which were conducted by a single team member, rather than the entire team. Though it was determined that the number and choices for site visits was sufficient for purpose of the current study, the inclusion of additional sites may have yielded additional relevant information.

\section{Results}

\section{Web Survey}

\section{Respondents}

There were 89 total responses to the 18-question Web survey. After excluding responses from those who had not actually implemented a link resolver, 79 responses remained. 5 products, 1Cate, Gold Rush, LinkSolver, Sirsi Resolver, and TOUR, garnered only 1 response each and were also eliminated from survey analysis. The remaining 74 surveys were used for purpose of analysis and comparison: 32 from SFX sites, 18 from Article Linker sites, 9 from LinkSource sites, 9 from LFP sites, and 6 from WebBridge sites. The vast majority of respondents had implemented a link resolver during 2003-2004. Most surveys, 50, were from 4-year degree granting institutions, 1 was from a 2-year degree granting institution, 3 were from special libraries (hospital or research), and the remaining 20 were submitted anonymously.

\section{Staffing Requirements and Expenditures}

Of the 18-questions on the Web survey, two assessed installation efforts, targeting staff time spent customizing the link resolver prior to and following rollout. Product 
customization is necessary to improve the patron interface and to configure the link resolver with local journals holdings information, ejournal and database platforms, and the ILS. Results (see tables 1 and 2) showed that the amount of staff time required to customize a link resolver was widely variable among the products. The ranking of products, in order of greatest amount of staff time required to customize to least is: LFP, SFX, WebBridge, LinkSource, and Article Linker. While $89 \%$ of LFP users spent $>40$ hours on customization prior to and post rollout, only $6 \%$ of Article Linker users spent $>40$ hours. It should be noted that the results for LFP far exceed those for any other product.

TABLE 1

Total Staff Hours Required to Customize Link Resolver Prior to Rollout (Reported as percentage of libraries responding)

\begin{tabular}{lccccl}
\hline & $\mathbf{0 - 1 0}$ & $\mathbf{1 1 - 2 0}$ & $\mathbf{2 1 - 3 0}$ & $\mathbf{3 1 - 4 0}$ & Over $\mathbf{4 0}$ \\
Endeavor LFP & $0 \%$ & $0 \%$ & $11 \%$ & $0 \%$ & $89 \%$ \\
Ex Libris SFX & $0 \%$ & $6 \%$ & $16 \%$ & $16 \%$ & $62 \%$ \\
III WebBridge & $0 \%$ & $0 \%$ & $17 \%$ & $33 \%$ & $50 \%$ \\
Ebsco LinkSource & $11 \%$ & $44 \%$ & $0 \%$ & $11 \%$ & $34 \%$ \\
SS Article Linker & $41 \%$ & $41 \%$ & $6 \%$ & $6 \%$ & $6 \%$ \\
& & & & \\
\hline
\end{tabular}

NOTE. 73 total libraries responded to this question. 9 LFP, 32 SFX, 6 WebBridge, 9 LinkSource, and 17 Article Linker.

TABLE 2

Total Staff Hours Required to Customize Link Resolver Post Rollout (Reported as percentage of libraries responding)

\begin{tabular}{lrrrrl}
\hline & $\mathbf{0 - 1 0}$ & $\mathbf{1 1 - 2 0}$ & $\mathbf{2 1 - 3 0}$ & $\mathbf{3 1 - 4 0}$ & Over 40 \\
Endeavor LFP & $11 \%$ & $0 \%$ & $0 \%$ & $0 \%$ & $89 \%$ \\
Ex Libris SFX & $9 \%$ & $16 \%$ & $6 \%$ & $13 \%$ & $56 \%$ \\
III WebBridge & $17 \%$ & $33 \%$ & $0 \%$ & $0 \%$ & $50 \%$ \\
Ebsco LinkSource & $11 \%$ & $33 \%$ & $33 \%$ & $0 \%$ & $22 \%$ \\
SS Article Linker & $41 \%$ & $24 \%$ & $24 \%$ & $6 \%$ & $6 \%$ \\
& & & \\
NOTE. 73 total libraries responded to this question. 9 LFP, 32 SFX, 6 WebBridge, 9 LinkSource, and 17 Article Linker.
\end{tabular}


To further evaluate staff time expenditures, two additional questions were posed in the Web survey. One question pertained to the job titles and percent of FTE devoted to ongoing operation and maintenance. This would include time spent maintaining journal holdings information within the link resolver and also time spent on improved customization, debugging, and product upgrades. The other question pertained to hours per week spent troubleshooting. According to the survey (see table 3), libraries devoted, on average, the most amount of staff time, $34 \%$, to the ongoing operation of LFP. Article Linker reported $25 \%$ and SFX reported 23\%. The least amount of staff time devoted was by LinkSource and WebBridge respondents-- $17 \%$ and $16 \%$ respectively. It must be stressed that this question asked amount of staff time devoted but not whether the amount was sufficient.

TABLE 3

Average FTE Devoted to Ongoing Operation of Link Resolver

$\begin{array}{ll}\text { Endeavor LFP } & 0.34 \text { FTE } \\ \text { SS Article Linker } & 0.25 \text { FTE } \\ \text { Ex Libris SFX } & 0.23 \text { FTE } \\ \text { Ebsco LinkSource } & 0.17 \text { FTE } \\ \text { III WebBridge } & 0.16 \text { FTE }\end{array}$

NOTE. 65 total libraries responded to this question. 8 LFP, 14 Article Linker, 29 SFX, 8 LinkSource, and 6 WebBridge.

While hours spent on weekly troubleshooting do not appear to correlate with FTE devoted to ongoing operation, it should be noted that troubleshooting is only one aspect of ongoing operation. And, it should be emphasized that this item did not address the sufficiency of staff time spent. According to survey results for hours spent 
troubleshooting per week, the greatest time spent to least was for: LFP, LinkSource, WebBridge, SFX, and Article Linker (see table 4).

TABLE 4

Hours Spent Troubleshooting Per Week (Reported as percentage of libraries responding)

\begin{tabular}{lccccc}
\hline & $\mathbf{0 - 5}$ & $\mathbf{6 - 1 0}$ & $\mathbf{1 1 - 2 0}$ & $\mathbf{2 1 - 3 0}$ & Over 30 \\
& $50 \%$ & $38 \%$ & $12 \%$ & $0 \%$ & $0 \%$ \\
Endeavor LFP & $78 \%$ & $22 \%$ & $0 \%$ & $0 \%$ & $0 \%$ \\
Ebsco LinkSource & $83 \%$ & $17 \%$ & $0 \%$ & $0 \%$ & $0 \%$ \\
III WebBridge & $87 \%$ & $10 \%$ & $3 \%$ & $0 \%$ & $0 \%$ \\
Ex Libris SFX & $94 \%$ & $6 \%$ & $0 \%$ & $0 \%$ & $0 \%$ \\
SS Article Linker & \multicolumn{7}{l}{} \\
NOTE. 70 total libraries responded to this question. 8 LFP, 9 LinkSource, 6 WebBridge, 31 SFX, and 16 Article Linker.
\end{tabular}

Product Performance

In order to assess product performance, a set of questions was asked pertaining to number of product complaints received from library staff and from library users. Complaint activity is somewhat reflective of staff and user expectations and therefore does not provide a direct measure of performance. It was hoped however, that trends or consistencies in data would emerge between performance-related questions. Unfortunately, for this item, only a single consistency appeared--for WebBridge, which received the most number of complaints from both population sets (see tables 5 AND 6). The discrepancies between complaints received from staff vs. users may be a reflection of differing levels of expectations for each population. This would need further study. 
TABLE 5

Number of Complaints Received Per Week from Library Staff

(Reported as percentage of libraries responding)

\begin{tabular}{llllrl}
\hline & & & & \\
& $\mathbf{0}$ & $\mathbf{1}$ & $\mathbf{2 - 5}$ & $\mathbf{6 - 1 0}$ & Over 10 \\
III WebBridge & $33 \%$ & $33 \%$ & $17 \%$ & $0 \%$ & $17 \%$ \\
Endeavor LFP & $25 \%$ & $50 \%$ & $12 \%$ & $0 \%$ & $12 \%$ \\
Ebsco LinkSource & $22 \%$ & $22 \%$ & $56 \%$ & $0 \%$ & $0 \%$ \\
Ex Libris SFX & $13 \%$ & $48 \%$ & $32 \%$ & $3 \%$ & $3 \%$ \\
SS Article Linker & $29 \%$ & $35 \%$ & $29 \%$ & $6 \%$ & $0 \%$ \\
& & & \\
NOTE. 71 total libraries responded to this question. 6 WebBridge, 8 LFP, 9 LinkSource, 31 SFX, and 17 Article Linker.
\end{tabular}

TABLE 6

Number of Complaints Received Per Week from Library Users

(Reported as percentage of libraries responding)

\begin{tabular}{lllrrr}
\hline & & & & \\
& $\mathbf{0}$ & $\mathbf{1}$ & $\mathbf{2 - 5}$ & $\mathbf{6 - 1 0}$ & \multicolumn{1}{c}{ Over 10 } \\
III WebBridge & $33 \%$ & $33 \%$ & $0 \%$ & $17 \%$ & $17 \%$ \\
SS Article Linker & $41 \%$ & $23 \%$ & $18 \%$ & $12 \%$ & $6 \%$ \\
Endeavor LFP & $38 \%$ & $50 \%$ & $0 \%$ & $0 \%$ & $12 \%$ \\
Ex Libris SFX & $26 \%$ & $45 \%$ & $29 \%$ & $0 \%$ & $0 \%$ \\
Ebsco LinkSource & $78 \%$ & $11 \%$ & $11 \%$ & $0 \%$ & $0 \%$ \\
& & & & \\
\hline NOTE. 71 total libraries responded to this question. 6 WebBridge, 17 Article Linker, 8 LFP, 31 SFX, and 9 LinkSource.
\end{tabular}

Another performance-related question was asked to determine percentage of online journals that successfully link at the article level. The results of the Web survey (see table 7) indicated that SFX had the highest percentage of article level linking, with $23 \%$ of survey respondents reporting article level linking for $>80 \%$ of online titles. WebBridge and LinkSource also provided fairly high percentiles. Article Linker and LFP incurred the poorest feedback. For each, $<7 \%$ of survey respondents reported article level linking for $>80 \%$ of online titles. 
TABLE 7

Percentage of Online Journal Titles that Link at Article Level

(Reported as percentage of libraries responding)

\begin{tabular}{lrrlll}
\hline & $\mathbf{0 - 2 0}$ & $\mathbf{2 1 - 4 0}$ & $\mathbf{4 1 - 6 0}$ & $\mathbf{6 1 - 8 0}$ & Over 80 \\
Ex Libris SFX & $0 \%$ & $3 \%$ & $37 \%$ & $37 \%$ & $23 \%$ \\
III WebBridge & $0 \%$ & $33 \%$ & $33 \%$ & $17 \%$ & $17 \%$ \\
Ebsco LinkSource & $22 \%$ & $11 \%$ & $33 \%$ & $22 \%$ & $11 \%$ \\
Endeavor LFP & $14 \%$ & $28 \%$ & $14 \%$ & $43 \%$ & $0 \%$ \\
SS Article Linker & $7 \%$ & $20 \%$ & $46 \%$ & $20 \%$ & $7 \%$ \\
& \\
\multicolumn{2}{l}{ NOTE. 67 total libraries responded to this question. } & & \\
\end{tabular}

Particular databases and electronic journal platforms are more advanced at working with OpenURL technology than others. Therefore, performance of a link resolver is, in part, dependent on which databases and electronic journal platforms are configured to work with the link resolver. In fact, as shown in table 8 , the majority of survey respondents identified poor OpenURL strings from the provider and platform-specific issues as being problematic. Also, at least half of respondents stated that platform and vendor specific performance issues were the cause of ongoing problems. Platforms identified as particularly troublesome in comments included: Gale, LexisNexis, and ProQuest.

Another set of problems that commonly affect the performance of OpenURL link resolvers are internal in nature. These are problems that fall within the link resolver's control. One such internal problem includes the ability to match on eISSNs. While only $9 \%$ of SFX respondents noted eISSNs as problematic, the numbers jumped to $11 \%$ for Article Linker, 22\% for LinkSource, 33\% for LFP, and 67\% for WebBridge. The ability to find electronic holdings was also noted as problematic by many respondents: $6 \%$ for SFX, 33\% for LinkSource and Article Linker, 50\% for WebBridge, and 67\% for LFP. 
Overall, respondents indicated less difficulty locating print holdings, but still, $22 \%$ of LinkSource respondents, $11 \%$ of LFP, $11 \%$ of Article Linker, and $6 \%$ of SFX indicating it as a problem. Zero WebBridge users indicated location of print holding as a problem.

An unintuitive user interface may be attributed to both internal and external factors. How a product looks "out of the box", how customizable it is, and what design-expertise is applied to the product will determine its ultimate appearance. The percentage of libraries noting unintuitive end-user interfaces as a problem was $28 \%$ Article Linker, $11 \%$ LinkSource, 11\% LFP, 9\% SFX, and 0\% WebBridge.

Taken into the context of internal and external problems, what resonates from the data is that SFX scored high for problems beyond its control and low for problems OpenURL linking technology can solve.

TABLE 8

Cause of Ongoing Problems with Link Resolver (Reported as percentage of libraries responding)

\begin{tabular}{|c|c|c|c|c|c|c|}
\hline & 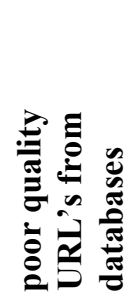 & 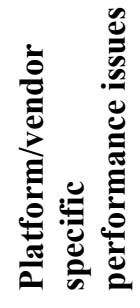 & $\frac{\mathscr{y}}{0}$ & 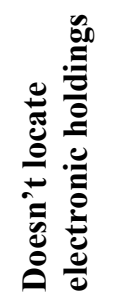 & 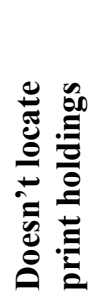 & 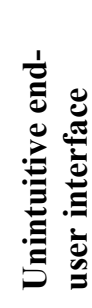 \\
\hline Ebsco LinkSource & $67 \%$ & $89 \%$ & $22 \%$ & $33 \%$ & $22 \%$ & $11 \%$ \\
\hline Endeavor LFP & $67 \%$ & $56 \%$ & $33 \%$ & $67 \%$ & $11 \%$ & $11 \%$ \\
\hline Ex Libris SFX & $66 \%$ & $56 \%$ & $9 \%$ & $6 \%$ & $6 \%$ & $9 \%$ \\
\hline III WebBridge & $67 \%$ & $67 \%$ & $67 \%$ & $50 \%$ & $0 \%$ & $0 \%$ \\
\hline SS Article Linker & $44 \%$ & $50 \%$ & $11 \%$ & $33 \%$ & $11 \%$ & $28 \%$ \\
\hline
\end{tabular}




\section{Self-Populating Interlibrary Loan Forms}

The remaining three Web survey questions pertained to self-populating interlibrary loan forms. As shown in table 9, the majority of survey participants reported that their link resolver did not have a self-populating interlibrary loan form. The only product with more than half of respondents reporting a self-populating ILL form was SFX (73\%). On the other end of the spectrum, only 14\% of LFP users reported self-populating ILL forms.

TABLE 9

Percentage of Products in Use at Libraries with Self-Populating ILL Forms

(Reported as percentage of libraries responding)

$\begin{array}{lr}\text { Ex Libris SFX } & 73 \% \\ \text { Ebsco LinkSource } & 44 \% \\ \text { SS Article Linker } & 41 \% \\ \text { III WebBridge } & 33 \% \\ \text { Endeavor LFP } & 14 \%\end{array}$

NOTE. 69 total libraries responded to this question. 9 LinkSource, 17 Article Linker, 6 WebBridge, 7 LFP, and 30 SFX.

The availability of self-populating ILL forms directly correlated with the number of erroneous forms received. Products that had higher numbers of self-populating ILL forms also had higher numbers of erroneous forms received (see table 10). Two factors that confound the data should be noted--it is unknown what the total volume of requests received by the libraries was; a library receiving greater numbers of requests overall may be more likely to receive more erroneous forms. Also, very few users of LinkSource, WebBridge, and LFP responded to the question. 
TABLE 10

Erroneous ILL Forms Received Per Week via Self-Populating ILL Forms

(Reported as percentage of libraries responding)

\begin{tabular}{lccccc}
\hline & & & & & \\
& $\mathbf{0 - 1}$ & $\mathbf{2 - 5}$ & $\mathbf{6 - 1 0}$ & $\mathbf{1 1 - 2 0}$ & Over 20 \\
Ex Libris SFX & $53 \%$ & $12 \%$ & $23 \%$ & $6 \%$ & $6 \%$ \\
SS Article Linker & $57 \%$ & $28 \%$ & $0 \%$ & $14 \%$ & $0 \%$ \\
Ebsco LinkSource & $33 \%$ & $67 \%$ & $0 \%$ & $0 \%$ & $0 \%$ \\
Endeavor LFP & $100 \%$ & $0 \%$ & $0 \%$ & $0 \%$ & $0 \%$ \\
III WebBridge & $100 \%$ & $0 \%$ & $0 \%$ & $0 \%$ & $0 \%$ \\
& \\
\hline
\end{tabular}

\section{E-Mail Survey}

There were 25 total responses to the 6-question e-mail survey. The surveys represented: 10 SFX, 3 Article Linker, 6 LinkSource, 4 LFP, and 2 WebBridge. Survey respondents were asked to identify how many electronic journals for which their library provided access. The mean for products ranged from a low of 8,400 for WebBridge to a high of 16,757 for SFX. The mean for all respondents was 14,477 .

To clarify staff time requirements, respondents were asked whether time spent on troubleshooting was sufficient. In most cases, respondents recognized a need to devote more time to troubleshooting and maintenance (see table 11). The rational for why the time was needed/not needed provided insight into the functionality and performance of various products. For SFX and LinkSource, at least one respondent indicated that more time was needed, but only to implement advanced customization. Article Linker and LinkSource each received a response indicating no problems had been reported. On the other hand, at least one respondent for LFP and WebBridge provided feedback that expressed product frustration. 
TABLE 11

Necessity to Devote More Staff Time to Troubleshooting and Maintenance

\begin{abstract}
SS Article Linker $\quad 3$ total responses. 2 libraries answered yes. Of these, 1 noted it wasn't pressing because no complaints had been received. 1 library responded no.

Ebsco LinkSource $\quad 6$ total responses. 3 libraries answered yes. Of these, 1 indicated the time would be spent on customization. 3 libraries answered no. Of these, 1 indicated that no complaints had been received.

Endeavor LFP 4 total responses. 2 libraries answered yes. 2 libraries answered no. Of these, both indicated that improvements were needed in LFP, but that the way the system was designed, it would not be worth the huge amount of effort needed to improve performance.

Ex Libris SFX 10 total responses. 7 libraries answered yes. Of these, 4 indicated that time would be spent on more customization and 1 indicated the time would be spent on usability testing and statistical analysis. 3 answered no because they felt that any additional enhancements or customization would meet with diminishing returns in performance.

III WebBridge

2 total responses. 2 indicated yes. Of these, 1 responded with reservations about putting more time into a product that wasn't meeting user expectations.
\end{abstract}

Because of the importance of an OpenURL link resolver's ability to link to journals at the article level, a question pertaining to percentage of article level linking was posed in both the Web survey and e-mail survey. Though the response rate for the e-mail survey was low, results for both surveys (see tables 7 and 12) show similar trends. The highest performing products in both cases were WebBridge and SFX, with the poorest ratings going to LFP and Article Linker. It is of interest to note that when asked in a separate question what expectations were prior to rollout, most libraries indicated that the actual percentage of article level linking post rollout was lower than had been expected prior to rollout. 
TABLE 12

Average Percentage of Online Journals that Link at Article Level

\begin{tabular}{lll}
\hline & Average & Range \\
III WebBridge & $83 \%$ & $80-85 \%$ \\
Ex Libris SFX & $79 \%$ & $50-95 \%$ \\
Ebsco LinkSource & $77 \%$ & $62-93 \%$ \\
SS Article Linker & $74 \%$ & $70-77 \%$ \\
Endeavor LFP & $50 \%$ & $50-50 \%$ \\
\hline
\end{tabular}

The last item assessed by the e-mail survey was rating of customer service. Article Linker was consistently rated as excellent, SFX was rated very good to excellent, LFP was rated poor to neutral, and LinkSource and WebBridge were consistently rated poor.

For ease of comparison, a consolidated table was created to represent results from the Web and e-mail surveys (see table 13). 
TABLE 13

Summary Table of Results

(Representing Tables 1-7, 9-10)

Lowest Rate

Highest Rate

\begin{tabular}{llllll}
$\begin{array}{l}\text { Staff hours required } \\
\text { to customize }\end{array}$ & SS & LinkSource & WebBridge & SFX & LFP \\
$\begin{array}{l}\text { Average FTE devoted } \\
\text { to ongoing operation }\end{array}$ & WebBridge & LinkSource & SFX & SS & LFP \\
$\begin{array}{l}\text { Hours spent } \\
\text { troubleshooting }\end{array}$ & SS & SFX & WebBridge & LinkSource & LFP \\
$\begin{array}{l}\text { Complaints received } \\
\text { from staff and users }\end{array}$ & LinkSource & SFX & LFP & SS & WebBridge \\
$\begin{array}{l}\text { \% of online journal titles } \\
\text { that link at article level }\end{array}$ & SS & LFP & LinkSource & WebBridge & SFX \\
$\begin{array}{l}\text { \% of products in use } \\
\text { at libraries with } \\
\text { self-populating ILL forms }\end{array}$ & LFP & WebBridge & SS & LinkSource & SFX \\
$\begin{array}{l}\text { Erroneous ILL forms } \\
\text { received via } \\
\text { self-populating ILL forms }\end{array}$ & & & & & \\
\hline
\end{tabular}

Site Visits

Five site visits were undertaken to evaluate the three products with the most promise for the UCL. The products included SFX, LFP, and Article Linker. Information obtained during the site visits was congruous with that previously derived from the Web and email surveys, but was significantly more detailed and illuminative. Information obtained served not only to support previously gathered knowledge, but augmented it with specific information about issues related to product implementation, maintenance, and performance, and to staff and user satisfaction. 
General Information Gathered by Product:

SFX

- SFX has the ability to:

- Search by ISSN and eISSN

○ Search by ISBN

○ Search by item title

○ Rank and display only the most appropriate copy

- Automatically load best copy of articles (one-click for users)

- Automatically load catalog record for print-only titles

○ Provide local dissertation information

- Pass citation information for all material types to ILL form

- Accurately run batch updates

- Allow serials librarian to control/edit holdings information most of the time

- SFX is available as a locally installed or hosted product. Outages do occur on the hosted server.

- Recommended skills include basic Unix and Perl.

- For basic functionality, not much customization is needed. Extensive customization options are available for both the locally installed and hosted products.

- Upgrades to the SFX software are time consuming. 
- Batch upload of local serials holding information is very accurate (approximately $95 \%)$.

- It is easy to prevent local holdings information from being overwritten by SFX updates.

- A negligible amount of time is required to maintain SFX.

- Maintenance of journal holdings information requires $1 / 2$ day per week. It is easy to add or change information to the KnowlegeBase from within the Web administration module. Staff with serials knowledge could add sites and targets or edit the information for specific journals. This includes rolling access, embargoed titles, and titles within aggregator lists.

- SFX has a test instance and a live instance.

- Problems: The major database problems occur with LexisNexis. Gale is also glitchy. Conference proceedings are problematic, but SFX can lead users to ERIC documents and customized dissertation information.

- The DD/ILL form is not always completely populated. The SFX citation matcher is a good tool for DD/ILL staff for verifying citations.

- Forms are built into the product for easy problem reporting.

- Overall, very positive impression of SFX.

\section{LFP}

- LFP has the ability to:

- Search by ISSN

- Search by ISBN 
- Automatically load best copy of articles (one-click for users)

- Automatically load catalog record for print-only titles

- Pass citation information for all material types to ILL form

- LFP implementation requires a huge effort.

- It takes approximately $20 \%$ of an FTE to maintain LFP.

- LFP has real problems resolving aggregator titles.

- Batch activation of journal holdings information is extremely inaccurate $(<20 \%)$. Both libraries visited track titles manually.

- There is no authority control or searchability of the KnowledgeBase. Therefore, it is difficult and time consuming to activate titles.

- Most of the initial implementation and much of the maintenance of the KnowledgeBase is done by scripting. Scripting and/or manipulation of XML files is required for addition of sites/targets/journals, holdings information for embargoed and rolling access titles, DD/ILL form, and statistical reporting.

- Problems: LFP cannot handle eISSNs. LFP does not work for conference proceedings, unless they have an ISSN or ISBN, and it does not work with theses or dissertations at all. LFP has difficulty accessing holdings information for individual titles within aggregator lists.

- Documenting problems with Endeavor is time consuming.

- The DD/ILL form is not always completely populated.

- Overall mixed reactions to LFP. 
Article Linker

- Article Linker has the ability to:

- Search by ISSN

○ Run against Serials Solutions information

- Pass citation information for records that contain an ISSN (only) to the

ILL form

- Implementing Article Linker can be done entirely by one serials staff in less than a week.

- It is remotely hosted and customization options are minimal. Serials holdings must be maintained within the Serials Solutions client. This holdings information functions as a KnowledgeBase for Article Linker. Print serials holdings can be added to the KnowledeBase.

- If the database has the ISSN and the journal is in Serials Solutions, Article Linker will find it.

- Problems: Article Linker cannot resolver non-article citations. Because the Article Linker button appears next to all citations, including non-article citations, in most databases, this is problematic. When used with non-article citations, Article Linker returns "no holdings" messages, even for those items held in the library. Article Linker cannot handle eISSNs, ISBNs, non-journal title searching of the catalog, theses, dissertations or conference proceedings. Also, vendor requirements dictate use of several versions of the Article Linker button between platforms. LexisNexis is not configured to run with Article 
Linker, as is the case with databases that do not include article citations (i.e. dissertation abstracts).

- Forms are built into the product for easy problem reporting.

- Overall satisfaction with product, but acknowledge low expectations.

\section{Discussion}

To our knowledge, this is the first study that critically analyzes and compares link resolver features and performance. Though this study began with a broad Web survey targeted at all users of commercially available OpenURL link resolvers, ultimately only three products were adequately evaluated. These products, in addition to being the most widely used in libraries, particularly those with large and diverse collections, were also the most compatible with UConn's Integrated Library System (ILS), Voyager, and Serials Management System, Serials Solutions.

\section{Ex Libris SFX}

SFX is an optimally performing OpenURL link resolver available as both a remotely or locally hosted product. We believe that given an appropriate investment of staff time and skill, SFX has the ability to outperform all of its competitors. SFX requires less staff time for ongoing operation and troubleshooting and matches on more publication types than comparable products. SFX is able to resolve appropriate local holdings for online and print journal articles (matching on both ISSNs and/or eISSNs), books, book chapters, ERIC documents, theses, dissertations, and Google Scholar. Maintenance of SFX itself is 
not an issue. SFX offers essentially a turnkey system for conducting batch uploads to the KnowledgeBase via the SFX Web-based administration tool. This tool also offers robust management reports for resources entered or deleted. SFX has a fully searchable KnowledgeBase that can easily manage embargoed and rolling access titles as well as eISSNs. Because of its ease of use, it would be possible for library serials staff to do the vast majority of SFX upkeep. However, as with most software products, it should be noted that SFX requires significant investment from appropriately skilled staff during implementation, for advanced customization, and during upgrades to the full product. SFX is the most widely used OpenURL link resolver on the market [12]. SFX customer service is rated very good to excellent by survey respondents and SFX training was rated as superb by site visit hosts.

\section{Endeavor LinkFinderPlus}

LFP is not a turnkey product. LFP requires significant and ongoing investment of serials and IT staff time to implement and maintain. Many of the WYSIWYG features included in SFX must be custom scripted in LFP. Problems with LFP KnowledgeBase, at best, greatly increase the amount of time required to track electronic journal changes and, at worst, make it impossible to maintain accurate holdings information. Specifically, it is not possible to run accurate batch updates of the LFP KnowledgeBase, there is no authority control in the KnowledgeBase, and the KnowledgeBase is not searchable in any manner. Further, it requires scripting and ongoing IT programming support to track journals that are embargoed or have rolling access. This means that LFP works, but does not work well for tracking complex journal holdings information. The same can be said 
for books and book chapters. Additionally, it does not match on eISSNs, nor can it resolve ERIC documents, theses and dissertations. It is not yet able to work with Google Scholar (it is in piloting). LFP has minimal statistic and reporting capabilities that do not require SQL Access queries. Though the institution that received a team site visit for LFP found customer support acceptable, this was not the experience reported by any library that responded to the e-mail survey.

\section{Serials Solutions Article Linker}

Article Linker is unique in comparison to SFX and LFP because it is only offered as a remotely hosted solution. Libraries using Article Linker, as with all other OpenURL link resolvers, must invest large amounts of staff time in tracking electronic journal changes. This time, though, accounts for nearly all the time necessary to operate Article Linker. Article Linker runs against Serials Solutions client information. Article Linker has the ability to find nearly $100 \%$ of electronic journals recorded in a library's Serials Solutions records if the database record contains an ISSN. Unfortunately, despite attractive staff time savings offered by Article Linker, this product fails to workfor any non-journal article citations or citations with eISSNs. Article Linker is limited to retrieval of electronic and print journal holdings and is only assured to accurately work for citations that include an ISSN. Article Linker will return "no hits found" messages for other publication types. Because many databases include significant amounts of non-article citations and the Article Linker button appears with each, the overall failure rate of Article Linker is extremely high. And, because Article Linker is a hosted solution, libraries have almost no ability to improve upon limited out-of-the-box features and 
screens. Article Linker is currently being piloted with Google Scholar. Despite product limitations, customer service is consistently rated as excellent for Article Linker.

It should be noted for all products that those able to accurately resolve citations from databases will be able to accurately populate Interlibrary Loan forms. Conversely, those products with poor ability to resolve citations from databases will have equally poor performance with Interlibrary Loan forms.

\section{Conclusion}

This study assessed the functionality and performance of commercially available OpenURL link resolvers to determine whether they could meet the needs of the University of Connecticut Libraries in providing accurate links to its broad array of materials; in the case of online materials, directly to the item, or in the case of print materials, to the proper holdings information. Of the three OpenURL link resolvers evaluated, only two were capable of working with more than journal article citations and thus only two could ultimately be considered for use at the UCL. These products were Endeavor's LinkFinderPlus and Ex Libris SFX. Based on this study, SFX was found to be more accurate and scalable than LinkFinderPlus in providing access from database level citations to corresponding full-text and/or local holding information. It has more flexibility and requires significantly less ongoing maintenance by both IT and serials staff. Given the limited staff resources at the UCL, the ability to manage electronic resources efficiently and effectively is paramount. SFX offers more robust usage 
statistics and provides management reports for resources added/deleted or updated from within the SFX Web-based administration tool. Further, SFX has, by far, the largest share of the market. Considering that the success of an OpenURL link resolver depends in part upon the active participation of electronic product vendors and that vendors will naturally choose to focus first and foremost on those products that serve the largest market, this was recognized as an asset.

Every library has different resources and needs. Because OpenURL link resolvers have a large impact on library staff, budgets, and users, libraries considering purchase of a link resolver must be highly selective in choosing one that fits within their financial and staffing capabilities. They should also consider how well a product integrates and functions with their ILS, serials management system, electronic journal and database platforms, and also how well it will meet the need and expectations of their staff and patrons.

\section{References}

[1] Brandsma, T.W., Bernhardt, E.R. \& Sally, D.M. (2002) Journal Finder: A solution for comprehensive and unmediated access to journal articles. Serials Review, 28 (1), 13-20.

[2] Caplan, P. (2001) A lesson in linking. Library Journal NetConnect supplement), 16-18.

[3] Chen, X. (2004) Assessment of full-text sources used by serials management systems, OpenURL link resolvers, and imported e-journal marc records. Online Information Review, 28 (6), 428-34.

[4] Cochenour, D., Jaramillo, G.R. \& Wilde, M. (2004) Access to e-resources: The implementation of SFX. Technical Services Quarterly, 21 (3), 25-39.

[5] Collins, M.D.D. \& Ferguson, C.L. (2002) Context-sensitive linking: It's a small world after all. Serials Review, 28 (4), 267-282.

[6] Colorado Alliance Gold Rush: A discovery and management tool for electronic resources. Retrieved January 5, 2006, from http://grweb.coalliance.org/

[7] Cummings, J. \& Johnson, R. (2003) The use and usability of SFX: Context-sensitive reference linking. Library Hi Tech, 21 (1), 70-84.

[8] Curran, M. (2001) SFX: Is it just special effects, or is this the missing digital link? The Serials Librarian, 41 (2), 21-7.

[9] Desmarais, N. (2003) For SFX see librarian. Against the Grain, 15 (3), 102-3. 
[10] Ebsco Industries Inc. Link source. Retrieved January 9, 2006, from http://www.linkresolver.com/

[11] Endeavor Information Systems Endeavor LinkFinderPlus. Retrieved January 4, 2006, from

http://www.endinfosys.com/prods/linkfinderplus.htm

[12] Ferguson, C.L. \& Grogg, J.E. (2004) October: OpenURL link resolvers. Computers in Libraries, 24

(9), 17-24.

[13] Fretwell-Downing Informatics Full-text linking -OL ${ }^{2}$. Retrieved January 5, 2006, from

http://www.fdisolutions.com/linking.html

[14] Geac Computer Corporation Limited Vlink information sheet. Retrieved January 5, 2006, from

http://www.library.geac.com/object/vlinkinfosheet_LIB.html

[15] Gerrity, B., Lyman, T. \& Tallent, E. (2002) Blurring services and resources: Boston College's

implementation of MetaLib and SFX. Reference Services Review, 30 (3), 229-41.

[16] Grogg, J.E. \& Ferguson, C.L. (2003) Linking services unleashed. Searcher, 11 (2), 26-31. Retrieved

January 3, 2006, from http://www.infotoday.com/searcher/feb03/grogg_ferguson.shtml.

[17] Innovative Interfaces Inc. WebBridge: Resource linking. Retrieved January 9, 2006, from

http://www.iii.com/mill/digital.shtml\#webbridge

[18] Lagace, N. (2003) The OpenURL and SFX linking. The Serials Librarian, 44 (1/2), 77-89.

[19] Machovec, G. \& Stockton, M. (2004) OpenURL link resolvers: A practical approach with Gold Rush.

Technical Services Quarterly, 21 (4), 1-16.

[20] Mcdonald, J. \& Coles, E. (2000) New technology: SFX. Cataloging \& Classification Quarterly, 31

(1), 84-6.

[21] Needleman, M. (2002) The OpenURL: An emerging standard for linking. Serials Review, 28 (1), 74-

76.

[22] Openly Informatics 1Cate. Retrieved January 5, 2006, from http://www.openly.com/1 cate/

[23] Ovid Technologies Inc. Ovid LinkSolver. Retrieved January 4, 2006, from

http://www.linksolver.com/site/index.jsp

[24] Rogers, M. (2003) Ebsco publishing releases LinkSource Open URL tool. Library Journal, 128 (1), 29.

[25] Schneider, K.G. (2001) SFX: A linkalicious service. American Libraries, 32 (6), 118.

[26] Serials Solutions (2006). Article Linker ${ }^{\mathrm{TM}}$. Retrieved January 9, 2006, from

http://www.serialssolutions.com/articlelinker.asp

[27] Sirsi Corporation Sirsi Resolver. Retrieved January 4, 2006, from

http://www.sirsi.com/Sirsiproducts/openurl.html

[28] Soderdahl, P.A. (2003) Implementing the SFX link server at the University of Iowa. Information

Technology and Libraries, 22 (3), 117-119.

[29] Sutherland, A. \& Green, P. (2004) An OpenURL resolver (SFX) in action: The answer to a librarian's prayer or a burden for technical services? Victorian Association for Library Automation (VALA)12th

Biennial Conference and Exhibition. Melbourne, Australia.

[30] TDNet TDNet the OpenURL link resolver. Retrieved January 4, 2006, from

http://www.tdnet.com/site/page.asp?ID=458A\&Parent=457

[31] Turner, S. (2004) Resource integration in the library: Link resolvers and federated searching.

Mississippi Libraries, 68 (3), 63-6.

[32] Van De Sompel, H. \& Beit-Arie, O. (2001) Generalizing the OpenURL framework beyond references to scholarly works. D-Lib Magazine, 7 (7/8). Retrieved January 3, 2006, from

http://www.dlib.org/dlib/july01/vandesompel/07vandesompel.html.

[33] Van De Sompel, H. \& Beit-Arie, O. (2001) Open linking in the scholarly information environment

using the OpenURL framework. D-Lib Magazine, 7 (3). Retrieved January 3, 2006, from

http://www.dlib.org/dlib/march01/vandesompel/03vandesompel.html.

[34] Walker, J. (2003) OpenURL and SFX linking. The Serials Librarian, 45 (3), 87-100. 


\section{Appendix 1}

\section{Web Survey}

1) What product are you using for your link resolver?

$\begin{array}{ll}\square & \text { Endeavor LinkFinderPlus } \\ \square & \text { Ex Libris SFX } \\ \square & \text { Innovative Interfaces WebBridge } \\ \square & \text { Ovid LinkSolver } \\ \square & \text { Serials Solutions Article Linker } \\ \square & \text { Other }\end{array}$

2) When did you roll out your link resolver to library users?
2000
$\square \quad 2001$
$\square \quad 2002$
$\square \quad 2003$
$\square \quad 2004$
$\square \quad 2005$

3) How many total hours of work were required to customize your link resolver prior to roll out?
$\square \quad 0-10$
$\square \quad 11-20$
$\square \quad 21-30$
$\square \quad 31-40$
$\square \quad$ Over 40

4) Since roll out, approximately how many total hours of work have been devoted to customizing your link resolver?
$\square \quad 0-10$
$\square \quad 11-20$
$\square \quad 21-30$
$\square \quad 31-40$
$\square \quad$ Over 40

5) For those whose job responsibilities include the operation and maintenance of your link resolver, please list the position titles and percentage of FTE spent on link resolver issues. (i.e. network services librarian - 25\%)

6) On average, how many total staff hours per week are spent trouble-shooting problems with your link resolver?
$\square \quad 0-5$
$\square \quad 6-10$
$\square \quad 11-20$
$\square \quad 21-30$
$\square$ Over 30

7) On average, how many link resolver complaints or error reports do you receive per week from library staff?
$\square \quad 0$
$\square \quad 1$
$\square \quad 2-5$
$\square \quad 6-10$
$\square \quad$ Over 10

8) On average, how many link resolver complaints or error reports do you receive per week from library users?
$\square \quad 0$
ㅁ 1
$\square \quad 2-5$
$\square \quad 6-10$
$\square \quad$ Over 10

9) What percent of your electronic journals would you estimate link at the article level from your link resolver?

$\square \quad 0-20 \%$

$\square \quad 21-40 \%$

$\square \quad 41-60 \%$ 
$\square \quad 61-80 \%$

$\square \quad$ Over $80 \%$

10) Are there particular databases or platforms that do not function well will your link resolver?

11) What percentage of electronic journal problems would you estimate are attributable to poor Open URL strings sent by publishers, rather than link resolver software issues?

$\square \quad 0-20 \%$

$\square \quad 21-40 \%$

$\square \quad 41-60 \%$

$\square \quad 61-80 \%$

$\square \quad$ Over $80 \%$

12) Does your link resolver product have a self-populating interlibrary loan form?

$\begin{array}{ll}\square & \text { Yes } \\ \square & \text { No }\end{array}$

13) If your link resolver product has a self-populating interlibrary loan form, how many incomplete or otherwise improperly populated ILL requests are received per week?
$\square \quad 0$
$\square \quad 1$
$\square \quad 2-5$
$\square \quad 6-10$

$\square \quad$ Over 10

14) What percentage of total ILL requests received in your library come through your link resolver?
$\square \quad 0-20 \%$
ㅁ $21-40 \%$
$\square \quad 41-60 \%$
ㅁ $61-80 \%$
ㅁ Over $80 \%$

15) What types of statistics does your link resolver report?

16) When deciding upon database and ejournal platforms, do you select or restrict your choices based on link resolver compatibility?

$\begin{array}{ll}\square & \text { Yes } \\ \square & \text { No }\end{array}$

17) Please check the items which cause ongoing problems with your link resolver?

$\begin{array}{ll}\square & \text { poor quality URLs passed from databases } \\ \square & \text { eISSN passed from databases rather than print ISSNs } \\ \square & \text { platform or vendor specific performance issues } \\ \square & \text { unintuitive end user interface } \\ \square & \text { link resolver doesn't consistently locate electronic holdings } \\ \square & \text { link resolver doesn't consistently locate print holdings }\end{array}$

18) Comments 


\section{Appendix 2}

\section{E-Mail Survey}

1. How many ejournal titles are you providing access for?

2. Approximately how many of those work effectively with your link resolver, actually linking at the article level?

3. Prior to implementation, what percentage of ejournal titles did you expect would link at the article level?

4. If you had unlimited staff, would you devote more staff to the ongoing maintenance, customization, or troubleshooting of your link resolver? Why or why not?

5. How do you rate the vendor customer service? It is sufficient to meet your needs? If no, please describe what is lacking?

\section{Appendix 3}

\section{Script for Site Visits}

1. What catalog do you have? Does it contain electronic journals holdings information?

2. Does the link resolver run separate searches run against the electronic journals list and catalog?

3. How many ejournal titles are you providing access for?

4. Approximately how many of those work effectively with your link resolver, actually linking at the article level?

5. Prior to implementation, what percentage of ejournal titles did you expect would link at the article level?

6. Do you provide direct access to full-text if it is available? For both PDF and HTML? How is this working?

7. Who implemented your link resolver? What skills did they need?

8. Who currently maintains your link resolver? What skills do they need?

9. If you had unlimited staff, would you devote more time to the ongoing maintenance, customization, or troubleshooting of your link resolver? Why or why not?

10. How do you rate the vendor customer service? Is it sufficient to meet your needs? If no, please describe what is lacking.

11. Is the vendor facilitative in sharing enhancements and/or workarounds to the link resolver?

12. Do you do batch updates of your KB? What percentage of the titles match?

13. Does your KB employ authority control for site/title entries?

14. How complete is your $\mathrm{KB}$, are there missing sites/targets that you are aware of?

15. Can you search your KB, if yes, what fields/tags are supported?

16. How often is your KB updated, and by whom?

17. Can you add sites/targets as you become aware of changes, how simple/difficult is this to accomplish?

18. Can you easily modify the output string delivered from the KB? For example if the string says retrieve this abstract..... when in fact users can get the fulltext, can you modify this?

19. What are the biggest problems that interfere with the performance of your link resolver?

20. With your extended services, do you run searches against your catalog and electronic journals list? Are they ISSN or journal title searches? Have you noticed any problems because of the specific type of searches you run? What happens to searches where the database provides no ISSN?

21. Do databases display links to your link resolver from non-article citations (i.e. books, book chapters, and conference proceedings)? If so, how do you handle non-article citations within your 
link resolver? Within your ILL form? Were these custom solutions? Do they work well for each publication type?

22. How does your link resolver work with eISSNs? These may be passed via PubMed.

23. How does your link resolver handle bad data passed via the OpenURL?

24. Do you have any way to get around or clean-up bad data from the OpenURL (i.e. removal of the leading "the" from titles)?

25. Have you opted to withhold or have you withdrawn your link resolver from specific databases or ejournal packages because of performance issues?

26. Is there anything else, positive or negative, that you'd like to tell us about your link resolver experience? 